\title{
A aula de História: a experiência e a biografia docente na produção do conhecimento escolar de História
}

\author{
History class: experience and teacher biography in producing school \\ knowledge
}

\section{Clase de Historia: experiencia y biografía del profesor en la producción del conocimiento escolar}

\author{
Everton Carlos Crema' \\ Universidade Estadual do Paraná, Professor. \\ https://orcid.org/0000-0002-1931-6019
}

Resumo: A discussão encaminhada vai ao encontro das condições e possibilidades de criação/ construção das aulas de história desenvolvidas por professoras e professores da rede pública de ensino de União da Vitória, PR, tendo como perspectiva de mediação a experiência profissional docente, a cultura escolar, o currículo e a diversidade de metodologias de ensino-aprendizagem. Discutir o processo criativo dos conteúdos e metodologias do ensino escolar de História apresentase fundamentalmente importante e necessário, pois se desenvolvem dentro de relações e alcance mais pragmáticos e em resposta a questões mais próximas e urgentes às escolas. Em contraste às continuadas sucessões, sobreposições curriculares, à falta de uma formação continuada eficaz e à distância formativa da universidade, desenvolvem-se, por parte de nossos professores, estratégias didático-metodológicas autorais no ensino escolar de História. Precisamos olhar para as condições e práticas de ensino de História que se desenvolvem nas salas de aulas de nossas escolas, buscando nesse processo uma aproximação entre os níveis escolares e de formação docente. Por meio de pesquisas da biografia profissional docente e da análise das práticas didáticometodológicas, percebemos em reflexo que elas se desenvolvem próximas à experiência profissional e à cultura escolar e, sobretudo, compartilham de um espectro metodológico diverso e próximo do que convencionamos chamar de produção estética da aula. Nesse sentido a pesquisa aplicada

Doutor em Educação, área de cultura, escola e ensino, pela Universidade Federal do Paraná; Mestre em História, área de cultura e poder, pela Universidade Federal do Paraná. 
dentro das escolas ultrapassa a idealização e formalização do currículo e busca construir um desenho didático mais próximo da realidade do ensino.

Palavras-chave: Metodologia de ensino. Didática da História. Biografia docente. Produção estética da aula.

Abstract: The discussion hat continues together with the conditions and possibilities of creation / construction of history classes developed by teachers of the public school of União da Vitória, PR, having as perspective of mediation the teaching professional experience, the school culture, the curriculum and the diversity of teaching-learning methodologies. Discussing the creative process of the contents and methodologies of history school teaching is fundamentally important and necessary, as they develop within more pragmatic relationships and reach and in response to questions that are closer and more urgent to schools. In contrast to the continuing successions, curriculum overlaps, the lack of effective continuing education and the formative distance from the university, our teachers develop authoritative didactic-methodological strategies in the teaching of history. We need to look at the conditions and practices of teaching history that develop in the classrooms of our schools, seeking in this process an approximation between school levels and teacher deformation. Through research of professional teaching biography and analysis of didactic-methodological practices, we reflect that they develop close to professional experience and school culture, especially share a diverse methodological spectrum and close to what we conventionally call the aesthetic production of the class. In this sense, research applied within schools goes beyond the idealization and formalization of the curriculum and seeks to build a didactic design closer to the reality of teaching.

Keywords: Teaching methodology. History Didactics. Teaching biography. Aesthetic production of the class.

Resumen: La discusión que continua cumple con las condiciones y posibilidades de creación / construcción de clases de historia desarrolladas por profesores de la escuela pública de União da Vitória, PR, teniendo como perspectiva de mediación la experiencia profesional docente, la cultura escolar, el currículum y la diversidad de metodologías de enseñanza-aprendizaje. Discutir el proceso creativo de los contenidos y las metodologías de la enseñanza de la escuela de historia es fundamentalmente importante y necesario, ya que se desarrollan dentro de relaciones y alcances más pragmáticos y en respuesta a preguntas más cercanas y más urgentes para las escuelas. En contraste con las sucesiones continuas, las superposiciones curriculares, la falta de educación continua efectiva y la distancia formativa de la universidad, nuestros maestros desarrollan estrategias didácticometodológicas autorizadas en la enseñanza de la historia. Necesitamos observar las condiciones y prácticas de enseñanza de la historia que se desarrollan en las aulas de nuestras escuelas, buscando en este proceso una aproximación entre los niveles escolares y la deformación de los maestros. A través de la investigación de la biografía de enseñanza profesional y el análisis de prácticas didácticometodológicas, reflejamos que se desarrollan cerca de la experiencia profesional y la cultura escolar, especialmente comparten un espectro metodológico diverso y cercano a lo que convencionalmente llamamos la producción estética de la clase. En este sentido, la investigación aplicada dentro de las 
escuelas va más allá de la idealización y formalización del currículo y busca construir un diseño didáctico más cercano a la realidad de la enseñanza.

Palabras clave: Metodología de enseñanza. Didáctica de la historia. Biografía docente. Producción estética de la clase.

Recebido em 3 de setembro de 2019

Aceito em 23 de março 2020

Publicado em 22 de julho de 2020

\section{INTRODUÇÃO}

0 presente trabalho é parte de minha pesquisa doutoral, defendida em março de 2019, pelo Programa de Pós-graduação em Educação (PPGE) da Universidade Federal do Paraná (UFPR), sob orientação da Dra. Maria Auxiliadora Schmidt, na qual investigamos a relação do currículo com a cultura histórica e a cultura escolar de docentes nos processos de ensino-aprendizagem, especificamente as formas e condições metodológicas autorais desenvolvidas no ensino escolar de História. Valorizamos abordagens biográficas docentes, dada a significativa autonomia de nossas professoras e professores no ensino escolar de História e os problemas e dificuldades crônicos da educação brasileira. Buscamos perceber em que condições e de que maneiras os professores de História produzem e ensinam em suas salas de aula, ante a diversidade de metodologias, práticas e processos. Por fim, evidenciou-se uma estrutura predominante básica chamada de "produção estética da aula", sobretudo por articular e relacionar uma diversidade significativa de elementos da experiência e cultura escolar, linguagem, imagens e cultura histórica construídas dentro de universos escolares e seriações específicas extremamente adaptáveis e dinâmicas do ensinar.

$\mathrm{Na}$ direção de evidências mais pragmáticas, próximas do cotidiano de ensino, analisaremos uma série de fragmentos das entrevistas realizadas com 27 professoras e professores do ensino fundamental e médio da rede pública da Cidade de União da Vitória, PR, e, para isso, baseamo-nos em modelos de análise e questões qualitativas segundo LessardHébert, Goyette e Boutin (1990). A constatação de que, em grande parte, os próprios docentes indicam uma forte relação da experiência profissional e da personalidade com o ensino e suas metodologias sustenta uma abordagem biográfica da pesquisa. Dessa forma, analisar a história biográfica se torna fundamental para podermos perspectivar as condições formadoras desse processo e a relativa importância implícita. Para Tardif (2014), a separação dos elementos pessoais e profissionais dos professores não contempla a absorção da personalidade docente nos processos quotidianos determinantes na realização do trabalho pedagógico. 
É evidente que os números da amostragem representam uma parte menor em relação a toda categoria profissional. Mesmo assim, os critérios e a abordagem da pesquisa qualitativa, de caráter biográfico, permitem a construção de reflexões em torno dos dados resultantes das entrevistas. De outra forma, não buscamos criar critérios e percentuais específicos sobre a qualidade e a efetividade docente ou outra coisa, mas, sim, perceber em que condições perceptivas e criativas os docentes olham para o currículo, o planejamento, a carreira, a didática e a metodologia de ensino, e mais detidamente como os professores produzem e estabelecem relações de ensino mobilizando um conhecimento científico em direção a um conhecimento didático ou, se preferirmos, à própria aula.

Conceitualmente percebemos a possibilidade de separarmos os elementos pessoais e privados dos docentes da sua condição profissional; entretanto, no trabalho pedagógico a eficiência do ensinar se estabelece positivamente pela qualidade da sincronia estabelecida entre esses universos. A produção do conhecimento possui uma relação direta com a própria experiência, que em termos de aprendizagem se constitui em metodologias de ensino, um conhecimento específico do trabalho docente. Segundo Goodson (2008) as diversas mudanças educacionais contemporâneas e seus processos se constituíram de forma impositiva, chocando-se com as missões e perspectivas biográficas do professorado. “Com muita frequência, a 'personalidade de mudança' foi considerada um obstáculo para a verdadeira reforma e não um módulo crucial para sua realização." (G00DSON, 2008, p. 109). A desvalorização da relação integradora entre a experiência docente e as exigências e expectativas profissionais advém de um crescente controle técnico-governamental sobre os processos de ensino e agendas educacionais.

\section{BIOGRAFIAS PROFISSIONAIS NO ENSINO}

Para nós, o estudo da biografia docente se apresenta fundamental na compreensão das relações do ensino e da criação estética da aula, dada a considerável autonomia e autoria dos professores, em termos didáticos e metodológicos. Perceber a experiência docente em trajetórias biográficas equivale a desenvolver estratégias compreensivas de suas práticas de ensino. Nesse sentido, apresentaremos as narrativas docentes e suas apreensões em dois eixos, um ligado ao planejamento escolar e outro relativo ao currículo, buscando perceber como nossas professoras e professores pensam o ensino. Analisando 
as falas docentes optamos por colocar acima das citações selecionadas as questões que as motivaram, facilitando a compreensão dos contextos, sua direção e intenção. ${ }^{2}$

Como você planeja os conteúdos anuais?

0 planejamento anual, além do que eu já respondi anteriormente, da conversa com professores, porque a gente não faz hoje um planejamento sozinho, a gente faz quase que dentro da área, que seria naquela semana que a gente tem no início do ano pra fazer o planejamento todo. Então, pra começar, eu vou pegar como exemplo o sexto ano: eu começo assim, com o título "o início de tudo", e ai eu dou continuidade, e o que eu falo pros meus alunos: "A história é uma continuidade". Existem hoje várias propostas de se trabalhar a História de uma maneira diferente; não sei se eu sou muito tradicional ou não, mas eu, por exemplo, eu não vou trabalhar num sétimo ano sobre maias, incas e astecas, sobre os indigenas, sem antes ter trabalhado o descobrimento do Brasil, ou o descobrimento da América. (Professor 07).

Como você planeja os conteúdos anuais?

Então, quando o colégio tem uma proposta pedagógica curricular, a gente primeiro olha o que que foi discutido nessa proposta e qual que é essa estrutura que o colégio segue, tem uma estrutura pra seguir. E dentro daquela estrutura, dentro daquilo que é pensado pelo colégio, a gente vai escolhendo os conteúdos. Partindo da Proposta Pedagógica Curricular a gente escolhe os conteúdos, alguns deles aparecem depois, então por isso eu acho importante essa questão de ter um replanejamento mesmo, porque alguns conteúdos que você pensa - e o engraçado é que você pensa às vezes sem conhecer a turma. (Professora 13).

Como você planeja os conteúdos anuais?

Bom, quando eu tenho tempo de sentar e pensar em como planejar, eu busco alguma coisa que possa me dar um suporte na sala de aula, fazer uma mídia, música, letra de música, um recorte de filme, alguma coisa assim, e planejo muito; às vezes saio bastante daquilo que eu já pensei, com as questões contemporâneas, com o que tá na mídia, no momento, a gente faz a ligação passado-presente, como que essa estrutura política de hoje se perpetuou, que caminho eles fizeram até chegar no momento que eles estão, é a partir disso. (Professor 03).

No que você se baseia para preparar suas aulas?

No currículo, eu preciso primeiro saber o conteúdo por turma, pra depois você preparar as aulas. Você precisa ter uma base teórica e a partir daí você vai preparar um esquema, vai utilizar o livro, vai utilizar uma música, algum trecho de documentário ou algum filme. Primeiro você tem que saber o conteúdo pra daí, a partir daí, preparar sua aula. Então, quando surgir dúvida, o que é normal, primeiro você tem que estudar. E buscar na fundamentação teórica, mas você vai ter que transformar isso na linguagem

2 Os fragmentos das entrevistas utilizados permitirem a análise da própria linguagem e a forma de construção do pensamento histórico dos professores e seu ensino. As falas refletem a sequência de construção do conhecimento escolar de história e precisam apresentar detalhes que, por vezes, na linguagem formal, são desconsiderados ou diminuidos. As citações informam as experiências biográficas de ensino extremamente acessíveis e compressiveis e não se constituem em fragmentos acadêmicos ou falas coordenadas, refletindo, dessa forma, o processo de construção estética da aula. 
do aluno, porque não adianta você utilizar uma linguagem que o aluno não vai entender. (Professora 18).

No que você se baseia para preparar suas aulas?

Na verdade, o preparo das aulas, já tenho as aulas mais ou menos preparadas. Então o que eu tento perceber, eu faço um plano de trabalho docente, mas aí no dia a dia eu tenho que sentir a turma, então se a turma é uma turma mais fraca, eu procuro atividades que venham a reforçar, se é uma turma que pega mais rápido, aí eu vejo outro tipo de material. (Professor 09).

No que você se baseia para preparar suas aulas?

No nosso planejamento, baseado a partir do currículo do Estado do Paraná, mais no planejamento que a gente se baseia pra preparar as aulas, e também, assim, o tempo de aula que a gente tem, da carga horária que tem aqui no colégio, que são ensino médio 128 aulas, e no ensino fundamental, 256. Então também penso nesse tempo e também pensando na realidade dos alunos, porque daí, às vezes você pega um currículo que tenha aqueles conteúdos que às vezes você vai trabalhar, mas que não vai dar o tempo, que não tem a ver com os alunos, os conteúdos que você está trabalhando. (Professora 06) (informações verbais).

Analisando as falas docentes, percebemos que os planejamentos desenvolvidos pelos professores possuem algumas diferenças de processo e organização em razão dos diversos modelos e tipos de ensino realizados e da trajetória profissional. Todavia, os fragmentos das entrevistas apontam algumas características e condições que permitem identificar processos comuns de produção do conhecimento escolar. As professoras e os professores citados planejam seus conteúdos de ensino e seus planejamentos anuais de forma conjunta ou sob consulta; buscam desenvolver coerência narrativa entre os conteúdos; utilizam o currículo nos planejamentos; enfatizam o caráter dinâmico do planejamento; informam experiências conflituosas entre os conteúdos escolares e as exigências curriculares; incluem no planejamento a diversidade de fontes e materiais; baseiam o planejamento nos conteúdos e não nas expectativas de aprendizagem; manifestam preocupação com a adaptação didática do conteúdo ao aluno; usam linguagem acessível e conteúdos sociais próximos; criticam o volume do conteúdo do currículo.

Podemos perceber as condições dinâmicas da produção do planejamento escolar e a preocupação docente em organizar conteúdos e exigências legais dentro de um universo didático, prevalecendo o interesse da aprendizagem e os contextos escolares mais imediatos. Também, em certa confusão, algumas perspectivas de planejamento docente se confundem com a própria didática do ensino, e as metodologias de trabalho docente, ainda que próximas, são distintas em termos de objeto e reflexão educacional. Notadamente, os docentes apresentam suas impressões sobre o planejamento a partir da experiência em sala de aula e de uma visão, em certa medida, formalista sobre o planejamento. Suas respostas 
sobre o planejamento escolar refletem suas compreensões e distinções, entre um documento burocrático/administrativo e a experiência e dinamicidade das aulas.

Em continuidade analisaremos fragmentos das falas docentes sobre o currículo e suas relações:

Qual a importância do currículo?

Eu acho que toda; quando a gente constrói um currículo, você pensa nos conteúdos e você dá o direcionamento do teu trabalho. Tem uma carga ideológica nesse direcionamento, tem uma perspectiva de ensino e de aprendizagem, uma visão de escola, então eu acho que é total a gente discutir currículo, aproximar com outros professores, com outras áreas. Seria importante nesse sentido de que, se isso não acontece, a escola não tem um direcionamento. Eu sempre brinco, é como se a escola fosse um barco a remo e cada um remasse pra um lado. Então, se não tem uma perspectiva do que que a escola se propõe a fazer, que tipo de individuo ela se propõe a formar? $E$ isso passa a ser pensado primeiro também no currículo. Toda essa carga curricular. (Professor 02).

Qual a importância do currículo?

0 currículo, na verdade, é colocado pra que a gente trabalhe o que tá dirigido pelo governo, que ele quer que a gente trabalhe, mas também fica como figurativo; a gente segue, mas que a gente trazendo coisas que a gente acha que dá certo no dia a dia do aluno, conforme a escola, conforme a clientela, alunos da cidade, alunos do campo. Dessa forma que pelo menos eu vejo que se forma, não posso premiar uma coisa só, um tipo de aula, de conteúdo. (Professora 14).

Qual a importância do currículo?

Eu acho que é através dele que você pega o embasamento, o conteúdo, o que você vai trabalhar. Você não pode simplesmente ficar, é, como é que eu posso te explicar? Se ele é tão importante assim pra você ministrar? Eu acho que ele é importante sim, na minha maneira de entender. Você tem que ter uma sequência, você tem que ter um parâmetro, você tem que ter um suporte, é um suporte. Aquele currículo que tá ali você sabe que você pode acrescentar alguma coisa, você não pode fugir daquilo que tá ali, faz parte, eu acho. Já foi especificado que tem que ser assim - não que ele tem que ser estático, você pode. Mas ele é base, você não tem como fugir, acho que é embasamento, que você vai explicar isso daí. (Professora 08).

As alterações curriculares interferem no ensino e na docência?

Eu acho que sim, me desculpe se não for bem explicado e bem colocado. Eu acho que quando você começa a engrenar, aquilo ali já [...] diz que é necessário a mudança, obvio, né, mas eu vejo dificuldade, eu pelo mesmo sinto, não sei se é porque eu sou do tempo antigão lá, mas eu vejo, dificultase para você montar um esquema depois, todo um trabalho. (Professora 06).

As alterações curriculares interferem no ensino e na docência? Não, eu acho que não, eu acho que ela vai alterar quando o professor fica preso a um modelo; mas quando você tem, por exemplo, uma linha de trabalho, essa linha de trabalho, é, pressupõe um trabalho sério com 
a disciplina de reflexão, de construção, de efetivação de conhecimento e de aplicação de conhecimento [...] Interfere se você usa aquilo como caixa, mas se você tem na tua cabeça uma ideia do que é História, do que que ela serve, o que que eu quero com isso, eu acho que ela é um norteador, sabe. Deu pra entender aí? (Professor 01).

As alterações curriculares interferem no ensino e na docência? Interfere no sentido, na docência, é um trabalho a mais que a gente tem que ter. A carga horária nossa já é grande, então é um trabalho a mais, trabalho muito grande, e depois você tem que adaptar tudo isso pelo que o governo quer, ele quer que agora seja assim, então esse você adaptar. $E$ como eu falei, o governo pede muita coisa, mas ele não te dá recurso pra isso. (Professora 11) (informações verbais).

As visões presentes nos depoimentos docentes sobre o currículo ensejam uma perspectiva distinta das análises sobre o planejamento, demonstrando uma visão singularizada e desconexa dos processos de ensino. Sobre o currículo qualificam-se algumas perspectivas: reflete-se uma concepção de ensino-aprendizagem; crítica ao distanciamento entre os documentos de ensino e a escola; crítica à indefinição curricular e seu caráter figurativo; pensam o currículo como estrutura de ensino; crítica à sucessão e descontinuidade curricular; e defendem o currículo como uma estrutura dinâmica e autônoma. A percepção dos professores sobre o currículo e sua dinâmica reflete em parte seu caráter prescritivo e distante da escola, dada a pouca ou nenhuma participação docente. Somam-se as dificuldades de apropriação dos documentos de ensino em meio à sua sucessão e sobreposição, como no caso paranaense. A dificuldade de compreensão do currículo e sua contribuição dentro dos processos de ensino-aprendizagem são significativas, pois devidamente pesadas as críticas, os currículos apresentam concepções de ensino-aprendizagem que podem vir a diminuir os equívocos no ensino escolar.

Numa tentativa de análise conjunta das falas docentes, das dificuldades de separação dos campos, buscaremos depreender a dimensão do universo do conhecimento do professor ou, mais detidamente, como ele cria, mobiliza e utiliza metodologicamente esse conhecimento na sala de aula, ensinando. Em geral, as falas estão ligadas ao cotidiano escolar, fortemente sustentadas no trabalho profissional desenvolvido e experienciado conjuntamente. Também, em alguns momentos, as perguntas feitas dão vazão a críticas e posicionamentos que afetam e afligem a docência a ponto de aparecerem como características e evidentemente postas nos depoimentos. Podemos perceber que o conhecimento que o professor cria e mobiliza reflete os problemas de toda ordem que afetam direta ou indiretamente o processo de ensino, independentemente de origens, responsabilizações e sua eventual resolução.

De certa maneira, isso demostra a visão metodologicamente unificada do processo de ensino, ao mesmo tempo em que apresenta a variedade dos constitutivos e perspectivas envolvidos, pois as maneiras com as quais os professores lidam com o conhecimento e 
o ensino refletem criativamente, em contramedida, as naturais dificuldades do campo. $\mathrm{Na}$ estratégia de ensino, a "mobilização estética da aula" não se assenta exclusivamente sobre as relações de ensino-aprendizagem ou conhecimentos científicos da disciplina de referência; ela mobiliza um conjunto de conhecimentos, memórias, práticas, metodologias, tempo, recursos didáticos, equipamentos, resultados anteriores, emoções, juízos de valor e os contextos sociais imediatos.

Pelos fragmentos analisados dentro do universo do conhecimento percebemos que os docentes desenvolvem:

Quadro 1 - Práticas e reflexões no ensino-aprendizagem

\begin{tabular}{|c|l|}
\hline Ações & Práticas e reflexões no ensino-aprendizagem \\
\hline 01 & O planejamento anual coletivo \\
\hline 02 & Consulta aos projetos político-pedagógicos do colégio e ao currículo oficial \\
\hline 03 & Desenvolvimento de uma coerência estrutural dos conteúdos \\
\hline 04 & Uso de fontes e linguagens de ensino diversas \\
\hline 05 & Busca por contextualização e relacionamento dos conteúdos \\
\hline 06 & Uso do livro didático \\
\hline 07 & Experiência como forte componente de ensino \\
\hline 08 & Observância aos contextos sociais dos alunos \\
\hline 09 & Perspectivas multidisciplinares \\
\hline
\end{tabular}

Fonte: os autores.

Todavia, as informações recolhidas apresentam perspectivas biográficas da carreira docente que são, em verdade, maneiras, procedimentos, entendimentos, apropriações e metodologias nas quais os professores apresentam distintivamente como pensam e fazem a educação. ${ }^{3}$ De outra forma, nas semanas pedagógicas os professores de História de um colégio, quando assim acontecer, reúnem-se e trocam informações, compartilham planejamentos de outros anos, reformulam e adicionam conteúdos e modificam critérios e formas avaliativas, e isso não acontece ao acaso ou ao sabor da mudança. Os depoimentos coletados demonstram que os professores se mantêm muito próximos da experiência e daquilo que entendem como um ensino eficiente, medido também pela satisfação docente em

3 Na direção das discussões realizadas indicamos os seguintes autores de referencia: Apple (1997), Arroyo (2011, 2014), Goodson (2013), Tardif (2014) e Yong (2010). 
suas aulas, pelos índices de reprovação e nota geral da turma e pela própria relação pessoal com seus alunos, forte indício da qualidade das aulas, ainda que mediada pela personalidade.

Pra fazer um planejamento aqui é só eu, não tem mais ninguém da área de história. Mas quando tô em outra escola que tem, a gente se reúne, discute o plano do planejamento, quais conteúdos a gente vai frisar, porque são vários professores e que os alunos podem estar mudando de turma, ou até mesmo de escolas, que eles possam chegar lá e ter o que eu tô trabalhando com essa turma aqui, sétimo $A$ da manhã, e o professor do sétimo $B$ da tarde possa contemplar o aluno com o mesmo processo de continuidade daquilo que eu tô trabalhando. (Professora १1).

Bom, em primeiro lugar nós escolhemos o livro didático, e através dele nós vamos vendo o que cabe a cada disciplina. Então a gente monta aquele plano, o plano docente que nós entregamos pra pedagoga. São em números de quatro, primeiro, segundo, terceiro e quarto bimestre, e através dali nós vamos trabalhando. Mas a gente não deixa de trabalhar só aquele conteúdo, uma data comemorativa, algo assim que surge da atualidade e também momentos, que de repente eu planejo a minha aula pra hoje e tal coisa, mas tem uma outra coisa então eu vou ocupar aquele espaço pra aquela atualidade. (Professor १२).

Eu acho que essas coisas sempre têm que estar mudando, mas temos que partir de uma discussão coletiva dos professores, fazendo uma avaliação, uma análise do que que precisa melhorar ou não. Mas aqui, ao menos aqui na escola tem um planejamento, e tem procurado seguir isso, sem interferência do que vem ou que não vem, e sempre tentando fazer uma avaliação do que que isso tem de importância, não se deixando levar assim por coisas que venham, ou que impõem pra gente. (Professora 06) (informações verbais).

Outro aspecto a ser considerado nas entrevistas é a preocupação com o desenvolvimento da coerência estrutural dos conteúdos de História a serem ensinados. Em alguns fragmentos percebemos a presença da perspectiva linear e tradicional da disciplina, em outros uma abordagem mais temática do ensino preocupada com a continuidade entre os assuntos. Aqui precisamos lembrar como os livros didáticos em geral são divididos, ou mesmo que colégios possuem coleções de livros didáticos distintos, diferentes também em sua organização curricular. Baseados nos depoimentos docentes coletados, percebemos que as divisões didáticas tradicionais dos conteúdos mantêm forte presença na prática docente, o que também se tornou verdade para o livro didático. Nessa direção é importante compreendermos que, durante a vigência dos Parâmetros Curriculares Nacionais, não existiam conteúdos curriculares específicos, mas, sim, eixos estruturantes com amplas perspectivas de abordagem. Em consequência, a ausência de um conteúdo formal transformou-se de possibilidade de ensino em dificuldade para o professorado. Exemplarmente: "Você tem que ter uma sequência, você tem que ter um parâmetro, você tem que ter um suporte; é um suporte." 
(Professora 15, informação verbal). Porém, é preciso deslocar a perspectiva do professor para o aluno com relação a uma coerência dos conteúdos, pois os alunos possuem mais dificuldades de compreensão e abstração a respeito dos conteúdos descontinuados dos livros didáticos que seus professores.

Evidente que no processo de ensino os problemas de coerência ou sequência dos conteúdos históricos/seriação são substituídos pela estrutura curricular do livro didático, escapando à ideia de uma dificuldade no ensino para o professor, ainda que deva ser considerada. Isso evidencia uma preocupação com a eficiência e a eficácia do ensino com relação ao aluno, que também está inserido na cultura escolar e, cognitivamente, ligado pela experiência discente à linearidade das teorias de ensino tradicionais. Antes de pensarmos os modelos didáticos e metodológicos de ensino em contradição, acreditamos que, em regra geral, os professores convergem assentidamente em direção aos consensos de interesse mediados, em que os costumes do aprender, as formas do ensinar orientam o agir.

Claro, tem a normativa da BNCC, das diretrizes do colégio, mas você joga, por exemplo, o que seria interessante naquele ano, e à medida que $o$ ano vai acontecendo, de acordo com a forma que a turma for respondendo, você traz isso ou aquilo. Por exemplo, tem momentos em que trabalhar as grandes navegações não é tão significativo quanto trabalhar as populações indígenas, mas em outros momentos eles querem e a coisa caminha pra aquilo. Então ele é uma diretriz, ele não é fixo, podem ocorrer mudanças surpreendentes. (Professor 01).

É aquilo que te falei no início, eles têm algumas discrepâncias, e a gente tenta achar um meio termo a fim de não prejudicar os alunos, porque se precisa contemplar algumas questões. Pela experiência a gente sabe quais questões são fundamentais em determinada série, que depois vai ser complementada na outra. Então a gente aproxima dessa maneira. É preciso ter um jogo de cintura e é preciso ter um pouco de conhecimento pra poder fazer isso. (Professor 07).

Eu acho fundamental, a gente teve algum tempo atrás nessa discussão por causa do Parâmetro Curricular Nacional. Eu vejo um esvaziamento de conteúdo na disciplina de História, porque - não é que eu não concorde que tem que priorizar história do Brasil, a história regional, história local, eu acho importantíssimo isso, mas por outro lado você não tem que descartar a história antiga e idade média, que eu acho assim, empobreceu muito o conteúdo, e ficou muito pobre. Essa é a minha opinião, é a minha opinião acerca disso. (Professora 13) (informações verbais). 


\section{LINGUAGENS, TÉCNICA, EXPERIÊNCIA E A PRODUÇÃO ESTÉTICA DA AULA}

0 uso de fontes e linguagens de ensino pelos professores demonstra reciprocamente a autonomia, o domínio e a autoria docente nas aulas de História, além de se constituírem em formas de conhecimento socialmente construídas em sua variedade e representatividade social. Notadamente, precisamos observar que os usos das fontes históricas não podem ser vistos unicamente como ferramentas ou complementos didáticos, pois estaríamos restringindo toda sua carga de conhecimento inerente relativo. Em geral, o uso das fontes está associado didaticamente aos conteúdos escolares de forma complementar, mas é preciso perceber que em vários momentos, nas entrevistas, diversas professoras e professores afirmam se utilizarem de fontes variadas como objetos de conhecimento, centrais no desenvolvimento do conteúdo escolar e próximas aos contextos sociais e às capacidades de aprendizado de seus alunos.

A utilização de fontes diversas em sala de aula, dada a sua materialidade e uso prático, vem ao encontro das metodologias de ensino mais pragmáticas desenvolvidas e utilizadas pelos docentes no ensino. Aulas menos abstratas facilitam aos alunos a compreensão dos conteúdos históricos, aumentam o nível de interesse discente, enriquecem a narrativa didática e demonstram que o professor domina uma variedade e diversidade maior do conhecimento histórico, pois, ao deixar o livro didático de lado, tem "meritosamente" reconhecido seu status como bom professor. Já as linguagens de ensino, também utilizadas na leitura interpretativa das fontes, não podem ser confundidas com o conteúdo específico do conhecimento a que fazem referência. Por essa condição, as linguagens de ensino como fotografia, música, pintura, teatro e jornais são metodologias de ensino específicas que se articulam com o conhecimento histórico, suas condições de apresentação, representação e compreensão. As linguagens de ensino utilizadas de forma adequada e observado o necessário domínio técnico produzem, em relação aos conteúdos vinculados, um significativo ganho cognitivo, pois, além de materializarem as discussões propostas em um tema das aulas de História, auxiliam em sua diversidade e proximidade social relativa à experiência do aluno, da família, do bairro.

0 debate proposto também se evidencia pelos resultados do Projeto Tecnologias e Linguagens para o Ensino de História, ${ }^{4}$ realizado com 21 docentes da disciplina dos $\uparrow 5$ colégios

4 Projeto Tecnologias e Linguagens para o Ensino de História, financiado pela Fundação Araucária, edital PRPPG/UNESPAR 014/2017. Coordenação de Everton Carlos Crema, com dois bolsistas de graduação. Buscou analisar as condições técnicas e de infraestrutura nas relações de ensino-aprendizado entre as linguagens de ensino e suas respectivas tecnologias em 15 escolas do Município de União da Vitória, entrevistando 21 professores de História dos ensinos fundamental e médio da rede pública de ensino. 
da rede estadual de ensino. As professoras e os professores entrevistados demonstraram utilizar cotidianamente fontes históricas diversas em suas aulas, ainda que reconheçam um domínio específico e limitado sobre seus usos. Também percebemos, em termos teóricos, certo desconhecimento e desarticulação entre as tecnologias de ensino e as linguagens de ensino. Entretanto, no avançar das entrevistas, as narrativas dos professores deixam claro o uso eficaz das fontes históricas. Pontualmente, ante a dificuldade de definir e diferenciar teórica ou metodologicamente seu trabalho com as diversas fontes históricas em suas linguagens, alguns docentes preferiram narrar passo a passo seu desenvolvimento, como faziam e como as associavam aos conteúdos trabalhados em sala e ao nível cognitivo de suas turmas.

Com certeza. Porque você ficar somente na linguagem oral, você só falando [..] Hoje em dia para a criança elas não conseguem manter o interesse, $e$ quando você usa dessas técnicas, você fala e eles estão vendo o que tá acontecendo. Então é muito importante porque na teoria é uma coisa, na prática é outra. E eu creio que nessas técnicas utilizadas eles conseguem ver, por exemplo: você vai dar uma aula sobre a segunda guerra. Se você traz aqueles filmes lá, algumas reportagens. Você falar é uma coisa, e eles verem, né? Alia a prática à oralidade. Eu acho que eles visualizam aquilo que você está utilizando na oralidade. (Professora 08 PIC PRPPG/UNESPAR 014/2017).

Reconheço sim, porque faz parte do cotidiano dos alunos também, e isso contribui bastante para a aprendizagem dos educandos. Música uso pouco, apesar de gostar bastante de música, acho que conheço pouco para estar usando em sala de aula, mas acho que tem uma ligação muito forte com nossos alunos. Imagens e cinema é o que eu mais uso na sala de aula; a tv multimidia, data show e a literatura [...] Percebo que quando os alunos leem algum livro, apesar se ser uma literatura contendo História, eu acho que isso dá mais vida para a História, sinto um pesar de não ter mais literatura na minha formação. (Professor 10 PIC PRPPG/UNESPAR 014/2017).

São fundamentais para que o aluno consiga gravar melhor aquilo que ele está aprendendo. Eu sempre digo para eles que nós aprendemos de várias formas, né; com experiência você aprende mais, com a vivência você aprende mais. Então a visualização, muitas vezes, ela vem se adequar a esse quesito experiência, que você não tem em sala de aula. Então as imagens, enfim, como você vai apresentar essa matéria, a esquematização dessa matéria vai facilitar muito o aprendizado dos alunos. E as várias tecnologias são fundamentais, as várias linguagens ali, todas, elas podem ser usadas. (Professor 11 PRPPG/UNESPAR 014/2017) (informações verbais).

Para nós restou clara a capacidade didática desenvolvida pelos docentes em se utilizarem de fontes históricas diversas dentro de suas linguagens de ensino em uma perspectiva funcional/prática. Em suas narrativas, o caráter estético imaginativo foi retomado em seu processo, as descrições apresentadas demonstram um pensamento simbólico prático, em que as linguagens do ensino adquirem um formato figurativo. As imagens narrativas futuras rememoradas conduzem sequencialmente à reflexão do processo de ensino 
imaginativamente prático/cognitivo. Ou seja, os professores não imaginam ou criam sua aula em textos, em frases, em metodologias; eles fazem isso imaginando narrativas sequenciais didáticas continuadas, quadro a quadro, estrutura a estrutura, em que se articulam as formas de ensinar com as possibilidades de aprender dos seus alunos.

\begin{abstract}
É porque o horizonte de significância não abrange cada uma das situações dadas em que se encontra o agente, o qual se posiciona, através de cada uma e para além dela, é que os eventos podem ser extraídos do âmbito de uma significância previamente dada no mundo interpretativo e tornar-se eficaz para promover novas constituições de sentido. (RÜSEN, 2015, p. 54).
\end{abstract}

Segundo o autor, a significância construída em termos individuais nem sempre é decorrente de uma experiência imediata e pessoal. Frequentemente nos utilizamos de situações ou eventos outros, mas que indiretamente permitem um entendimento antecipado do cotidiano, fundamental para a orientação no tempo. Da mesma forma, os professores se utilizam de conhecimentos, memórias e estruturas compreensivas diversas, próprias e também dos alunos na produção da compreensão do conhecimento, pois compartilhamos, em termos de conhecimento, linguagem, cultura e experiência, um universo de significância e interpretação. Em parte, o resultado esperado pode ser exemplificado por meio de uma aproximação comum entre uma aprendizagem histórica significativa para o aluno e um processo de ensino didaticamente construído dentro dos referenciais historiográficos e teóricos do conteúdo trabalhado pelo professor. Toda a didática, a metodologia e o ensino-aprendizagem descritos e potencialmente realizados não são uma finalidade objetivada em si mesma, mas uma condição para a satisfação e a felicidade individual, tanto para os professores quanto para os alunos. Segundo Rüsen (2015, p. 55), o sofrimento, a angústia ou suas potências são a base da interpretação e da vontade histórica, "[...] do sofrimento da experiência se desprende a centelha de sentido de poder ser de outra forma." Os docentes, em seu trabalho de ensinar o conhecimento histórico, ultrapassam a historiografia em direção à geração de sentido crítico dos alunos, pois, em tese, já possuem a experiência compreensiva do processo histórico. Os professores buscam na efetividade da aula, na compreensão histórico-crítica significativa dos conteúdos por seus alunos e nas relações do conhecimento histórico com a vida prática a satisfação docente. "Há sempre igualmente uma busca de sentido, uma aspiração à felicidade, uma demanda utópica, que expande radicalmente o campo da experiência humana." (RÜSEN, 2015, p. 54).

Por essas perspectivas, compreendemos, em parte, os motivos pelos quais os professores "pouco" se aprofundam em leituras historiográficas ou mesmo em seus debates e revisionismos; assim, também o formato e a estrutura notadamente acadêmica da escrita historiográfica, distante de qualquer reflexão ou metodologia de ensino, é fundamentalmente importante para os docentes. Dentro das escolas e do cotidiano profissional os limites e 
condições de trabalho definem e priorizam ações e reflexões dentro de uma cultura escolar, assimilada consentidamente em um agir educativo. Suas preocupações se movem em direção à didática de ensino e às relações de aprendizagem discente. A criação "estética imaginativa" da aula exige um controle significativo sobre o conteúdo historiográfico, e seu processo didático de ensino pouco se aproxima da escrita científica da História. Também porque, em geral, nos cursos superiores de História, a didática e a metodologia de ensino ocupam lugares secundários, distanciados de uma educação histórica.

A formação acadêmica não dá conta, não dá, não dá porque no magistério, no exercício do magistério, da licenciatura, você tem quatro anos a maioria das licenciaturas, e ela não dá conta dos conteúdos do currículo. Não adianta dizer que dá. Então seria, nossa, de extrema importância que o professor ele tivesse uma formação continuada na área dele, e que ele fosse contratado na área dele, que ele ensinasse na área dele, e que essa formação continuada fosse na área dele e também formações de demanda, como das tecnologias, aproximação com outras áreas. (Professora 16).

A gente fez todas as mudanças. Foi pedido para que vissemos se os conteúdos estavam nas séries certas, nos anos certos, a gente olhou, fez e adequou, mas na realidade vem aquilo que eles querem. Um professor de universidade que nem sabe que essa escola aqui existe, colocando um conteúdo lá pra uma turma que ele não conhece, pra uma realidade numa escola que ele não conhece. (Professora 05).

É esse jogo de cintura que a gente tem que tá fazendo pra poder trabalhar em sala de aula; até porque, eu penso assim, na nossa própria formação, eu me questiono na questão que eu acho que a história temática no fundamental é muito dificil de ser trabalhada, mas eu também me questiono: por que eu também não fui ensinada assim? Então, talvez se eu tivesse tido uma outra formação fosse mais fácil pra mim. (Professor 07) (informações verbais).

A contextualização e a relação que os professores fazem dos conteúdos históricos e historiográficos ocorre majoritariamente, senão exclusivamente, em termos didáticos e dentro do universo do ensino de seus alunos. Esse lugar e mirada no ensino reproduz a vivência e o sentido do ensino de História para as professoras e os professores. Portanto, são as condições do ensino que estruturam os conteúdos históricos e historiográficos da aula, e não o contrário, processo reproduzido em antecipação no preparo das aulas. As entrevistas demonstram que a contextualização ocorre em níveis complementares; num primeiro momento, o conteúdo de História, a aula, são preparados em condições válidas adequadas às capacidades cognitivas/seriação dos alunos. Em outro, os conteúdos históricos escolares são contextualizados e relacionados a partir das condições sociais dos alunos, em suas realidades e vivências imediatas. 
Isso exige dos professores um conhecimento histórico e historiográfico significativo, sobretudo para poderem dialogar com o conteúdo histórico presente nos livros didáticos e respectivos planejamentos. Também para elucidar e desenvolver questões mais amplas e significativas surgidas nos contextos das aulas ou apresentadas pelos alunos, não somente pela demanda que os próprios conteúdos históricos ensejam, mas também pelo conhecimento social histórico que o aluno carrega e domina em graus e condições próprias. A contextualização e relação desenvolvida pelos docentes em suas aulas possui um caráter extremamente dinâmico, seja pela exigência da sequência curricular do conteúdo didático da história, seja pela diversidade das turmas e a variedade e multiplicidade de realidades vivenciadas por seus alunos. Nesse sentido, as experiências docentes práticas bem-sucedidas, em termos de aprendizado discente, tornam-se a base de estruturação da aula, mais acessiveis aos docentes. 0s professores podem retomar pela memória pessoal os processos, as fases em seu desenvolvimento, criando critérios de análise e validade efetivos. A perspectiva didática do ensino de História acaba determinando as reflexões sobre o ensino de História, pois em sua contextualização tudo é colocado em provisoriedade e complementariedade, seja o livro didático, a historiografia, o nível de atenção, os resultados, os discentes, etc.

\begin{abstract}
Eu acho que o currículo, às vezes, ele não se adapta ao aluno, então, como eu falei, nós temos problemas de linguagem, problemas de metodologia, e mesmo na proposta curricular das escolas às vezes você tem muitas temáticas do currículo e não fazem parte do cotidiano do aluno. E não parece haver pra ele nada que ele consiga relacionar, por mais que 0 professor se esforce, tenta trazer uma aproximação. Eu acho que essa aproximação fica muito difícil, e ainda nós temos dentro do currículo hoje organizado temáticas em que a escola oferece, tenta oferecer essas temáticas no currículo, e são temáticas de enfrentamento, são temáticas aí que são feridas sociais; e eu vejo que, às vezes, há uma resistência dos alunos em trabalhar essas temáticas, às vezes até dos professores, ou às vezes da escola como um todo. (Professor 03).
\end{abstract}

A gente tem aqui no Estado do Paraná as Diretrizes Curriculares que norteiam os conteúdos que a gente vai trabalhar em sala de aula, porém na disciplina de História - eu falo pela minha disciplina - dá uma diferença entre os conteúdos curriculares das Diretrizes com os livros didáticos. Então, o livro didático ele é baseado na história integral, e as Diretrizes orientam pra que a gente trabalhe a história temática. Então, o que que eu procuro fazer? Tentar dentro desses dois conteúdos flexibilizar as minhas aulas. Isso é uma opinião minha, eu no fundamental, eu não gosto de trabalhar com história temática, eu acho que não funciona tão bem como funciona no médio. Eu prefiro história integrada. Então eu procuro adaptar esse conteúdo pra trabalhar com os alunos pra que não fique - não é que fique perfeito, não fica, né, por mais que a gente tente, mas que não fiquem lacunas de conteúdos. (Professora 17).

Há um bom tempo, eu pego muito a situação em que a gente vive, o país, a situação econômica, a situação política, a vida dos alunos; eu tento sempre 
adequar os conteúdos que eu trabalho dentro daquilo que a gente está vivendo na atualidade; mas eu tento fazer assim com a vida, colocar dentro do nosso contexto de vida, que tudo o que já passou, alguém viveu, nós estamos. A história, eu acho que ela sempre muda os figurantes, mas a gente sempre está fazendo história, você tá lutando por alguma coisa. (Professora 13) (informações verbais).

\section{CURRÍCULO REAL E CONHECIMENTO SOCIAL NA SALA DE AULA}

0 livro didático aparece nas entrevistas sendo tratado de maneiras diferentes pelos professores; enquanto alguns sustentam que $\circ$ utilizam em todas as etapas do ensino, outros abertamente apontam seus problemas e limites, evidenciando seu caráter complementar. Porém, é importante mencionar que seu uso declarado e sua crítica foram evidenciados por todos os professores, o que remete ao entendimento de que todos conhecem o conteúdo escolar posto nos livros didáticos. 0s planejamentos anuais e diários dos professores levam em conta a estrutura curricular dos livros didáticos, o que, para Benito (2009), constitui-se em um "currículo editado", pois a organização dos livros didáticos baseia as aulas dos professores se desenvolvendo pela estrutura e organização dos conteúdos de História. Também não podemos deixar de evidenciar que os mecanismos de acompanhamento e controle da equipe pedagógica do colégio, dos alunos e dos pais sobre o ensino de História em termos de produtividade ocorrem em função do uso "adequado" e "sequencial" do livro didático, independentemente da qualidade das aulas, critério claramente mais subjetivo.

El manual escolar es un sintetizador de la cultura profesional de los enseñantes. En primer término, en cuanto producto adscrito como libretto al oficio de maestro, es un elemento adscrito al ajuar material de los profesionales de la enseñanza. Antes de generalizarse el uso de los libros por parte de todos los alumnos thecho que se origina en la sustitución del modelo de enseñanza individual por el de enseñanza simultánea a lo largo de la segunda mitad del siglo XIX-, el manual era propiedad de la escuela, y en ocasiones del propio maestro. Es dificil imaginar, históricamente o en la actualidad, un docente que no se asocie al uso de textos. También porque con frecuencia la autoría de estos impresos didácticos se adscribe a la condición de profesor. Finalmente, porque el libro escolar puede ser concebido, como sugiere Umberto Eco en un reciente artículo de prensa (1), como un magister del profesor, esto es, como un instrumento que instruye y educa a los propios enseñantes, en la medida en que en él se ofrecen muchas pautas metodológicas para la organización de su trabajo y contenidos culturales seleccionados para dotar de programa a su acción. (BENITO, 2009, p. 170). 
Novamente nos vemos entrelaçados por uma abordagem prática qualificada das aulas de História, tendo no uso do livro, no trabalho efetivo dos capítulos, um equivalente de maestria e comprometimento docente. Isso nos força a pensar uma visão de ensino extremamente materializada em resultados, em conteúdos dados, em exercícios e tarefas feitas, tudo muito concreto, medido e atestado por um trabalho verificável e palpável. Para os professores, o trabalho no ensino de História mais concreto e materializado em termos de conteúdo do livro didático acaba por se tornar um "lugar seguro", tanto em termos do conhecimento historiográfico quanto dos limites impostos pela eventual falta de domínio sobre o conteúdo didático-metodológico do ensino de História. Nesse sentido, entendemos que a construção "estética da aula" de História realizada pelos professores adeptos do uso mais restrito do livro didático realiza o trabalho imaginativo estético da sua aula muito próximo do conteúdo escolar de história e sua sequência didática. Entendemos que o trabalho docente no planejamento da aula, mais próximo da estrutura metodológica e do conteúdo do livro de história, dê ao docente uma segurança pessoal maior, em termos de ensino-aprendizagem, ainda que possamos inferir que, consequentemente, as possibilidades de contextualização do conhecimento histórico com a cultura escolar e a cultura social dos alunos venham a perder considerável fôlego.

Eu tenho utilizado, eu acho fundamental o livro didático porque é a base pro aluno, é o material que ele tem em mãos, impresso. Não que você não vá produzir outros materiais; a gente produz, mas não tem condições da gente produzir todo material o tempo inteiro pra eles. São muitos alunos, muitas turmas, saindo muito caro, e o livro tá ali, foi comprado com nosso dinheiro, foi pago, eu acho que tem que ser utilizado. A única coisa, assim, que eu acho em relação ao livro, que ele é muito criticado, eu penso que ele pode ser, sim, bem utilizado; qualquer texto pode ser bem utilizado em sala, depende da maneira que você vai abordar ele. (Professora 14).

Então, eu tenho, esse ano, por exemplo, a coleção Contato e Saber, aqui do colégio e pela minha surpresa ela não contempla a Guerra do Contestado, não tem uma só palavra sobre a Guerra do Contestado, então foi um livro construido num processo regional talvez mais específico de outros estados. Não se pensou nisso, que era espećfico nosso aqui. Então eu acho que o currículo não contempla. Outra coisa que eu vejo é a dificuldade na história africana e afro-brasileira, é uma presença muito superficial até, acho até pelas produções acadêmicas que agora estão se consolidando aqui no Brasil; então isso ainda não se traduziu numa poĺtica específica do livro didático, e esse conteúdo não aparece de uma forma efetiva no livro didático. Eles aparecem por força da lei, mas numa forma muito superficial; eu acho que teria que ser nos livros didáticos, ser mais aprofundado também. (Professor १२).

Desde que seja um livro didático bom, que seja aquele livro que eu escolhi pra minha escola, eu até utilizo um pouco mais, mas até hoje não veio nenhum livro que o professor escolheu na escola, nem qualquer livro [..] Porque eu tenho em várias escolas e cada escola escolheu um livro diferente. Cada escola escolheu um livro diferente, justamente por quê? 0 
livro que eu olhei lá o conteúdo tá se adequando pra aquela realidade, ali pra outra, ali pra outra. Então, assim que, não existe livro perfeito, não posso me apoiar só num livro didático, é importante se tivesse pra todos, mas não tem, não vem um número de livros que um sexto ano com quarenta alunos, vem dezoito livros, que é o que acontece, então, eu dispenso muito o livro didático, dispenso mesmo, não faço uso dele direto, de jeito nenhum. (Professora 14) (informações verbais).

Em contraponto, a experiência escolar dos professores em sua biografia profissional é notadamente um componente determinante nos processos criativos em todos os sentidos, lugares e perspectivas. Sua construção é também como a educação, um processo de produção e reprodução indeterminado; não que o conhecimento advindo da experiência não produza ação e objetividade, todavia os professores naturalmente apresentam dificuldades em especificar graus e condições para sua realização. Por outro lado, a experiência docente se apresenta individualmente como um conhecimento prático resolutivo, pois resolve algo ou uma situação abstrata, teórica e metodológica, que em seus próprios termos se apresenta como dificuldade para o desenvolvimento da aula em sua compreensão e domínio.

A experiência realizada em termos de ensino pelos professores em suas aulas os recoloca como produtores do conhecimento, integrando os conteúdos científicos da História às condições de compreensão do próprio conhecimento e de seus alunos. Posto isso, criam uma perspectiva valorativa e integradora do campo, permitindo aos professores desenvolverem e dominarem todo o processo de ensino-aprendizagem em relativa segurança. Nesse processo, o conteúdo de ensino produzido se torna um equivalente cognitivo compreensivo próprio, não demandando reflexões, análises e comparações de ideias outras. A autonomia e a relação direta do conhecimento escolar disciplinar construído, em mediação aos contextos da escola, é significativamente uma verdade prática adequada e próxima aos interesses e capacidades dos entes envolvidos. Os limites criativos, entremeados pelas experiências docentes e pessoais, também produzem em seu processo o erro; todavia, como o professor tem na experiência própria uma mediação entre planejamento e resultado, qualquer erro eventual, muito presente no ato de ensinar, será a posteriori corrigido, adaptado e melhorado pelo docente, até mesmo porque na perspectiva do erro se desenvolve um processo de superação pessoal em direção à validade da aula e à satisfação pessoal do professor.

Todavia, essa experiência é fundamental para a criação de arquétipos modelares sobre a docência, pois os mesmos mecanismos, dinâmicas, critérios e metodologias utilizados para aferir julgamento qualitativo sobre os outros também têm sua validade interiorizada como condições de julgamento e avaliação próprios. Evidentemente, o contato com experiências de ensino significativas de outros colegas se torna um caminho em possibilidade a ser percorrido, pois tendo conhecimento do percurso trilhado, as escolhas se tornam mais objetivas, quantificáveis e constatáveis pela experiência comparativa própria do docente, pela fala reputada de outros 
colegas e dos próprios alunos, que reconhecem, sim, processos de ensino de sucesso. Metaforicamente falando, a experiência docente se aproxima de um jogo virtual, de uma partida de videogame, em que todas as vezes em que o jogador perde, morre ou deixa de cumprir as devidas missões, o jogo se encerra; reiniciado, será retomado pela experiência (re)construída sobre novas bases, novas estratégias em "teatros de operação" distintos, mais relacionados e integrados pela experiência. "A experiência é a mais importante de tudo, né? É a experiência, né? Você só aprende se você fazer." (Professora 06, informação verbal).

Se eu fosse fazer o currículo hoje, eu ia pegar a vivência, eu ia pegar, assim, a nossa, a experiência do que você já vivenciou, o que você viu. Eu acho que eu ia tentar pegar assim as coisas, as que não deram certo e as que deram certo; eu ia tentar construir alguma coisa que pudesse discutir, tanto o que não deu certo e o porquê e o que deu certo e o porquê também que deu. É, eu penso assim, não sei. (Professor 01).

Acho que isso já tá meio que consolidado, acho que tem pouca discussão pra pensar, e às vezes a gente vai trabalhando sem muito se questionar da importância, da validade; porque tá ali, ela tava ali, quando você começou a dar aula você não questionava muito, e via o que os outros faziam, o que o currículo vinha pra fazer. Então acho que mais ou menos penso que há pouca discussão em cima disso daí. (Professora 15).

Acho que primeiramente é na realidade da escola, que eu trabalho em duas escolas; aqui o conteúdo funciona dessa maneira, o mesmo conteúdo lá na outra escola, que é outra realidade, vai ser de outra maneira. A questão assim até socioeconômica, lá vou ter um acesso, vou poder cobrar de uma maneira diferenciada, que tem uma maior participação dos pais, e já, que nem, por exemplo, na outra escola eu vou ter que ponderar, eu vou ter que cobrar mais o que acontece em sala de aula, não querendo cobrar as atividades que eles levam pra casa. (Professora 18) (informações verbais).

Os contextos sociais dos alunos se tornam componentes necessários fundamentais com relação ao ensino (professor) e à aprendizagem (aluno) de História, pois ensejam um processo compreensivo que entremeia experiência social, cotidiano e capacidades cognitivas distintas. A professora e o professor, ao vivenciarem a cultura da escola, acabam por assimilar toda uma estrutura e dinâmica social em correlação direta às comunidades nas quais se inserem; o conhecimento do processo e dos mecanismos sociais imediatos se torna equivalente ao ensino. Dessa forma, o uso das realidades e do cotidiano dos alunos, sua linguagem e práticas culturais informam um lugar e um momento ao professor sobre seus alunos. Como o ensino se desenvolve em termos interpessoais e de relação social, toda abordagem e perspectivação dos conteúdos históricos ensinados e problematizados feitas a partir do universo do aluno possuem um ganho qualitativo superior. Primeiro por mobilizar informação, linguagem, compreensão, signos e significados próximos e conhecidos dos alunos, o que facilita consideravelmente o processo de abstração cognitiva 
durante as aulas; e segundo, por apropriar o universo social imediato dos alunos em termos históricos, em que, naturalmente, as perspectivas críticas de mudança e transformação e o entendimento compreensivo resultam em "tomadas de consciência".

Além disso, quando a escola busca na comunidade formas de inserção e integração - ganho para todos é significativo; a comunidade passa a se ver e a se fazer representar junto à escola e aos educadores, compartindo demandas e também suas resoluções. Alunos e professores compartilham mais proximamente um universo comum construído, e essa valorização comum aproxima-os positivamente, criando canais de comunicação e resolução de conflitos mais amplos e eficientes, com distintos resultados educacionais. Também aos professores, ao se utilizarem dos contextos sociais imediatos da comunidade e da cultura da escola em suas aulas, aferem ganho qualitativo aos conteúdos, ao mesmo tempo em que desenvolvem continuadamente uma metodologia de ensino que se aproxima da "educação histórica"; mesmo sem um domínio metodológico específico, os docentes produzem em suas aulas uma compreensão histórica significativa, o que, em termos de ensino de História, se apresenta como extremamente desejável.

Nós temos que ter maturidade pra fazer uma espécie de eleição de conteúdos ou mesmo de enfoques que você vai dar pra aquela formação mais integral ao nosso aluno, ao objeto que é o nosso trabalho, que é o nosso aluno. A gente tem que estar se antenando pras realidades sociais $\mathrm{e}$ trabalhar essas realidades sociais em sala de aula, e às vezes um currículo muito rígido não permite isso, então a gente tem que fazer por forma transversal. (Professora 14).

Pesquisando, vai atrás, tô falando mais de história local e regional. Essa parte é bacana porque os alunos se interessam; você fala em história regional os alunos se interessam muito mais, porque ele diz: "A vó contou a história", então esse tipo de coisa a gente consegue aproximar o aluno da História. (Professor 03).

É justamente o que eu tava falando, ele tá muito distante da realidade do aluno, ele tinha que estar mais próximo, no meu ponto de vista. Por exemplo, um livro que eu vou ensinar no Estado do Paraná, ele tinha que tar tentando jogar toda a história, alguma história do Paraná. Falar da segunda guerra no livro didático um pouquinho, eu não vou nem falar de União da Vitória que eu sei que é radical demais, mas se eu tô no Estado do Paraná acho que o livro tinha que contar, por exemplo, a história da Segunda Guerra no Paraná, a imigração no Paraná, ou em Santa Catarina, pra não ficar um negócio muito vago; dai às vezes foge, tá! (Professora 11) (informações verbais).

As perspectivas multidisciplinares relatadas e usadas pelos professores em suas aulas integram os campos do conhecimento e aproximam o conhecimento científico disciplinar de seus usos cotidianos e da própria dinâmica dos conhecimentos. Em termos educacionais, 
os conhecimentos escolares são ensinados e perspectivados de forma singularizada, o que dificulta aproximá-los das realidades sociais. Integrar e articular os conhecimentos escolares é permitir aos alunos se apropriarem deles nas mesmas condições em que eles são produzidos e desenvolvidos socialmente. Quando os diversos conhecimentos científicos se desenvolvem em conjunto, suas dinâmicas explicativas se consorciam e se desenvolvem conjuntamente, criando condições ampliadas em variedade para a compreensão do conhecimento por parte do aluno.

Para o conhecimento histórico em específico, o desenvolvimento de abordagens educacionais multiperspectivadas no ensino se apresenta muito próximo aos constitutivos da didática da História e da própria escrita historiográfica, pois mobiliza dimensões distintas e diversas. Em termos didáticos, a multiperspectivação do conhecimento auxilia a compreensão dinâmica da História, escapando às visões tradicionais de linearidade e continuidade da História. Além disso, o próprio objeto da História, o homem, produz em seu devir todo tipo de conhecimento, informação e descoberta, em ampla e variada condição. Entretanto, os modelos tradicionais de ensino e o formato escolar pouco integram ou formam multidisciplinarmente o docente, pois mesmo sendo uma dinâmica do próprio conhecimento, em termos didáticometodológicos, os professores não são ensinados a conceber as áreas do conhecimento de forma integrada. Em resultado, acabam por desenvolver modelos de ensino baseados na experiência somada e dentro das expectativas de seus alunos, pois professores de História "devem ensinar História e não inventar moda." (professora 04) (informação verbal).

\footnotetext{
Então às vezes a gente até se frustra por causa disso, você faz um plano, um planejamento, um projeto - que nem agora, a gente vai ter agora em novembro a Semana da Cultura, a participação do pessoal da equipe interdisciplinar; nós estamos elaborando um tema sobre o meio ambiente, mas nem todos vão conseguir trabalhar o meio ambiente. (Professora 08).
}

Na realidade o que acontece, professor, é que tem a proposta, tem $\circ$ currículo, tem as diretrizes, mas o governo tá sempre mandando temas à parte pra você trabalhar. Estatuto do idoso, estatuto da criança e do adolescente, meio ambiente, vários outros temas que a gente não consegue juntar com uma coisa só, o que que a gente faz no caso? Aproveita e se apropria desse tema quando tá no conteúdo que encaixa, cabe encaixar [...] Mas a gente ainda traz algum texto sobre o tema, que é proposto trabalhar fora, o que não está no conteúdo básico mesmo e trabalha com eles, faz um trabalho à parte. (Professora 17).

Tem algumas coisas que eu trabalho, mas eu não dou enfoque tão grande, porque assim é todo ano. Com essa nova política, de se trabalhar o tempo todo $\circ$ índio, o negro, eu acho que na aula de História não dá pra se encaixar o tempo todo isso, eu acho que isso tem até uma pressão muito grande pra que se coloque. Trabalhar gênero, eu gosto de trabalhar, mas eu trabalho gênero em determinado tema, não tem como. Tem coisas que não tem como se estar trabalhando, ali guerras, ai você vai trabalhar gênero. (Professora 05) (informações verbais). 
A autonomia docente alcançada pelos professores de História sobrevém, grosso modo, de dois aspectos, um ligado à própria crise na educação brasileira, outro decorrente e relacionado à carreira e experiência docente. Durante décadas consecutivas, a experiência profissional docente em sua cultura escolar reagiu às descontinuidades e aos desinvestimentos crônicos na história da educação brasileira, com crescente autonomia e independência. Essa autonomia inicial de recusa se tornou uma visão de ensino materializada em metodologias e didáticas próprias e reativas em nível de apropriação e produção individuais. Ante a dificuldade de se propor efetivamente um projeto alternativo de educação, professoras e professores buscaram, em termos mais imediatos, contrapor-se aos descaminhos da educação, numa base de resistência política ampla individual, também catalisando e encaminhando as demandas do ensino em suas realidades.

\section{CONSIDERAÇÕES FINAIS}

Numa tentativa de síntese, buscamos apresentar alguns constitutivos presentes nas formas de produção, relação e integração do conhecimento, desenvolvidos no trabalho docente pelos professores, tanto em termos teóricos e abstratos quanto em perspectivas concretas e experienciais desenvolvidas no ensino, encaminhando a criação e o refletir sobre o ensino de História dentro de uma "estética criativa da aula". Esse processo e condição autoral dos docentes se desenvolve de maneiras personalíssimas, mas em observância aos critérios e conteúdos tradicionais do ensino de História, adaptados didaticamente aos contextos de ensino imediato, e vem definindo o tipo de aula de História e a maneira em que elas são "criadas", pois suas condições, lugares e personagens presentes no processo de criação "estética da aula" influenciam em muito a própria aula em seu encaminhamento. Nesse sentido, torna-se importante percebermos, em termos biográficos, como nossas professoras e nossos professores fazem seu trabalho ensinando, e a partir da realidade dada do ensino, pensar paralelamente processos educacionais, currículos, didáticas e metodologias.

De outra forma, a análise das condições de ensino-aprendizagem efetivas desenvolvidas por nossos professores precisam ser decompostas e percebidas em termos metodológicos no intento de melhorarmos a própria condição docente, criando um maior domínio e compreensão sobre os processos de aprendizagem ao mesmo tempo em que enriquecemos a docência. A reflexão e a pesquisa aplicada sobre os processos de ensino autorais dotariam os professores das condições de produção do conhecimento escolar tão importantes para o ensino-aprendizagem e a satisfação docente. Prescindimos da pesquisa 
escolar de abordagens mais pragmáticas, postas dentro das salas de aula, observando as condições reais do ensino escolar de História e a autonomia docente como um horizonte de possibilidade real, concreto e objetivo, ou então permaneceremos confortavelmente em nossos gabinetes universitários "profetizando" sobre o ensino-aprendizagem.

\section{REFERÊNCIAS}

APPLE, M. W. Conhecimento oficial: a educação democrática numa era conservadora. Petrópolis: Vozes, 1997.

ARROYO, M. G. Outros sujeitos, outras pedagogias. 2. ed. Petrópolis: Vozes, 2014.

ARROYO, M. G. Educador em diálogo com nosso tempo. Belo Horizonte: Autêntica Editora, 2011.

BENITO, A. E. El manual escolar y la cultura professionalo de los docentes. Tendências Pedagógicas, v. 14, p. 169-180, 2009.

GOODSON, I. F. As políticas de currículo e de escolarização. Petrópolis, RJ: Vozes, 2008.

GOODSON, I. F. Currículo: teoria e história. Petrópolis, RJ: Vozes, 2013.

LESSARD-HÉBERT, M.; GOYETTE, G.; BOUTIN, G. Investigação qualitativa. Fundamentos e práticas. Lisboa: Instituto Piaget, 1990.

RÜSEN, J. Teoria da história: uma teoria da história como ciência. Curitiba: Editora UFPR, 2015.

TARDIF, M. Saberes docentes e formação profissional. 17. ed. Petrópolis: Vozes, 2014.

YOUNG, M. F. D. Conhecimento e currículo: do sócio construtivismo ao realismo social na sociologia da educação. Porto, Portugal: Porto Editora, 2010.

Endereço para correspondência: Rua Coronel Amazonas, Centro, União da Vitória, Paraná, Brasil; evertoncrema@yahoo.com.br

Roteiro, Joaçaba, u. 45, p. 1-24, jan./dez. 2020 | e22983 |E-ISSN 2177-6059 